\title{
Correlation of Thrombin-Antithrombin Complex With Indoxyl Sulfate Level in Chronic Kidney Disease Patients
}

\author{
Irza Wahid $^{1}$, Nuzirwan Acang ${ }^{2}$, Syaiful Azmi ${ }^{3}$ \\ irzawahid_drsppd@yahoo.co.id \\ Hematology Oncology Medic Division, Internal Medicine Department, Medical Faculty, Universitas \\ Andalas, Dr. M. Djamil Padang Hospital ${ }^{1,2}$ \\ Nephrology and Hypertension Division, Internal Medicine Department, Medical Faculty, Universitas \\ Andalas, Dr. M. Djamil Padang Hospital ${ }^{3}$
}

\begin{abstract}
Thrombosis is the leading cause of mortality in chronic kidney disease (CKD) patients. The risk of thrombosis in CKD is related to increase of coagulation activity. The Thrombin Antithrombin complex (TAT complex) is a sensitive marker of thrombosis. The mechanism of occurrence of thrombosis in CKD is closely related to indoxyl sulfate uremic toxin. This study was conducted to see the correlation of TAT complex with indoxyl sulfate in CKD patients. A cross-sectional, analytic observational study conducted in stage 3-5 non-dialysis CKD patients at Dr. M. Djamil Padang Hospital. Of the 30 samples, there was a significant increase $(\mathrm{p}<0.05)$ of the mean levels of TAT complex and indoxyl sulfate respectively $12.61 \pm 2.49 \mathrm{ng} / \mathrm{ml}$ and $4.70 \pm 1.96 \mathrm{mg} / \mathrm{dl}$ compared to their normal values ( $0.5-10 \mathrm{ng} / \mathrm{ml}$ and $1.86 \pm 0.30 \mathrm{mg} / \mathrm{dl}$ ). There was a significant positive correlation between TAT complex and indoxyl sulfate levels $(\mathrm{p}<0.05 ; \mathrm{r}=0.52)$. There was an increase in TAT complex levels in CKD patients which indicated an increase in coagulation/thrombosis activity. Increased levels of indoxyl sulfate in CKD patients indicate the occurrence of accumulation of uremic toxins. The more increasing levels of indoxyl sulfate, the more increases the TAT complex level. The more accumulated the uremic toxin, the more coagulation/thrombosis activity increased. There was a significant increase in the level of TAT complex and indoxyl sulfate, and there was a significant positive correlation with moderate degree of TAT complex with indoxyl sulfate levels in CKD patients.
\end{abstract}

Keywords: Chronic Kidney Disease, Indoxyl Sulfate,TAT Complex.

\section{Introduction}

Coagulation is part of hemostasis process in order to maintain blood circulation system after vascular injury occurred. Chronic Kidney Disease (CKD) has been a global issue with high morbidity and mortality related to hemostasis disorder[1].

The manifestation of hemostasis disorder in CKD could be in two opposite condition, bleeding in one hand and thrombosis in the other hand. However, thrombosis has been known to play an important role in cardiovascular complication which caused death in CKD patients[1][2].

Meanwhile, Wattanakit $\mathrm{K}$ et al [3] in Longitudinal Investigation of Thromboembolism Etiology (LITE) study, found a higher risk of vein thromboembolism, 1.28 times higher in 
patient with mild renal insufficiency (GFR $60-90 \mathrm{ml} /$ minute $/ 1,73 \mathrm{~m}^{2}$ ) and 2,09 times higher in patients with CKD stage 3 or 4 (GFR $15-60 \mathrm{ml} / \mathrm{minute} / 1,73 \mathrm{~m}^{2}$ ). Ocak G et al. [4] in his study found a higher risk of venous thromboembolism, 2,5 times higher in a patient with moderate renal insufficiency (GFR 30-60 ml/minute $/ 1,73 \mathrm{~m}^{2}$ ). Meanwhile, it is 5,5 times higher in severe renal insufficiency $\left(\mathrm{GFR}<30 \mathrm{ml} / \mathrm{minute} / 1,73 \mathrm{~m}^{2}\right)$.

The increase of thrombosis risk in CKD is associated with the change of coagulation cascade, marked with the increase of coagulation activity[4]. Several prothrombic hemostasis mediators increased in CKD are fibrinogen, soluble thrombomodulin, soluble tissue factor, thrombin-antithrombin complex[5].

Indoxyl sulfate is one of the uremic toxins from protein bound-compounds group. Indoxyl sulfate originated from tryptophan amino acid which we can find in protein diets such as chicken, meat, fish, turkey, and beans. Tryptophan is metabolized then by the liver to be indoxyl sulfate. Indoxyl sulfate is normally secreted to urine especially with active secretion by proximal tubular. In patients with CKD, renal function disorder will lead to indoxyl sulfate accumulation in blood[6].

Indoxyl sulfate can be a marker of renal function decrease and also played an active role in disease progression. Wu IW et al. [7] found that indoxyl sulfate serum is associated with kidney disease progress. In another hand, Kikuchi et al. [8] found that indoxyl sulfate is the main serum metabolite that differs CKD with normal condition based on the examination of several toxin accumulating in $\mathrm{CKD}[8]$.

The increase of indoxyl sulfate in blood will increase the risk of thrombosis. Research showed that indoxyls sulfate would induce tissue factor expression in endothelial cells and vascular smooth muscle cells[9][10]. Gao C et al. [11] showed that indoxyl sulfate could activate phosphatidylserine of the cell membrane. The surface of cell and microparticle exposed with phosphatidylserine, in the end, will bound with factor Xa and complex prothrombinase and then accelerate thrombus forming.

Complicated hemostasis problem in CKD and tendency of prothrombic condition marked with an increase of coagulation activity, and also the role of the uremic toxin to hemostasis and its complication lead the author to investigate the thrombin coagulation activity represented by TAT complex and its correlation with indoxyl sulfate in CKD.

\section{Methods}

This study is observational analytic with a cross sectional method where independent variable and dependent variable are examined in the same time. This study takes place in Kidney-Hypertensive Division polyclinic and Internal Medicine Ward RSUP dr. M. Djamil Padang General Hospital. The sample is the patient who met the inclusion and exclusion criteria. The potential subject will be screened earlier, explained the research protocol, and asked for informed consent.

Inclusion criteria are patients with CKD stage 3,4 and 5, age between 16-60 years old, and agreed to get involved in this study. Exclusion criteria are pregnant women, a patient who underwent hemodialysis, receiving anticoagulant therapy, fibrinolytic, hormonal therapy, immunosuppressant, a patient with active bleeding, a patient with liver cirrhosis, a patient with sepsis or DIC, a patient with diabetes mellitus, a patient with CAD or stroke, a patient with malignancy, and also patient with chronic diarrhea. 
A patient who met the inclusion and exclusion criteria as many as 30 persons based on sampling calculation will be recorded for the data such as age and gender, then perform a check of TAT complex and indoxyl sulfate. The result will be analyzed statistically.

\section{Results}

From 30 samples, 13 persons $(43.33 \%)$ are male, and 17 persons $(56.67 \%)$ are female. The youngest age is 30 years old, and the oldest age is 60 years old. Age distributions are 30-40 years old; 4 persons (13.33\%), 41-50 years old; 10 persons $(33.33 \%), 51-60$ years old; 16 persons $(53.33 \%)$.

Table 1. Baseline Characteristics

\begin{tabular}{cll}
\hline \multicolumn{1}{c}{ Characteristics } & $\mathrm{n}(30)$ & $\%$ \\
\hline Gender & 13 & 43,33 \\
Male & 17 & 56,67 \\
Female & & \\
Age (years old) & 4 & 13,33 \\
$30-40$ & 10 & 33,33 \\
$41-50$ & 16 & 53,34 \\
$51-60$ & & \\
Stage of CKD & 8 & 26,67 \\
Stage 3 & 10 & 33,33 \\
Stage 4 & 12 & 40,0 \\
Stage 5 & & \\
Etiology & 17 & 56,67 \\
Hypertension & 6 & 20,0 \\
Gout Nephropathy & 4 & 13,3 \\
Obsonic Pyelonephritis & 3 & 10,0 \\
\hline
\end{tabular}

Based on stage classification of CKD, 8 persons (26.67\%) are CKD stage 3,10 persons (33.33\%) are CKD stage 4, 12 persons (40.0\%) are CKD stage 5. Based on etiology, 17 persons $(56.67 \%)$ are hypertension, 6 persons $(20.0 \%)$ are gout nephropathy, 4 persons $(13.3 \%)$ are chronic pyelonephritis, and 3 persons $(10.0 \%)$ are obstructive nephropathy.

Table 2. Mean Level of Indoxyl Sulfate in a patient with CKD and normal person

\begin{tabular}{|c|c|c|c|c|}
\hline \multirow[b]{2}{*}{ Variable } & & \multicolumn{2}{|c|}{ Mean $\pm \mathrm{SD}$} & \multirow[b]{2}{*}{$\mathrm{p}$} \\
\hline & & $\begin{array}{l}\text { Sample } \\
(\mathrm{n}=30)\end{array}$ & $\begin{array}{l}\text { Control } \\
(\mathrm{n}=20)\end{array}$ & \\
\hline $\begin{array}{l}\text { Indoxyl } \\
\text { (mg/dL) }\end{array}$ & Sulfate & $4,70 \pm 1,96$ & $1,86 \pm 0,30$ & $\mathrm{p}<0,05$ \\
\hline
\end{tabular}

Mean level of indoxyl sulfate in this study was higher than a normal person (control) $1,86 \pm$ $0,30 \mathrm{mg} / \mathrm{dL}$, and when it is compared with t-test, there is a significant difference $(\mathrm{p}<0.05)$. From 
the figure below, we can see the mean level of indoxyl sulfate in stage 3 is $2.79 \mathrm{mg} / \mathrm{dL}$, stage 4 is $4.22 \mathrm{mg} / \mathrm{dL}$, and stage 5 is $6.37 \mathrm{mg} / \mathrm{dL}$.

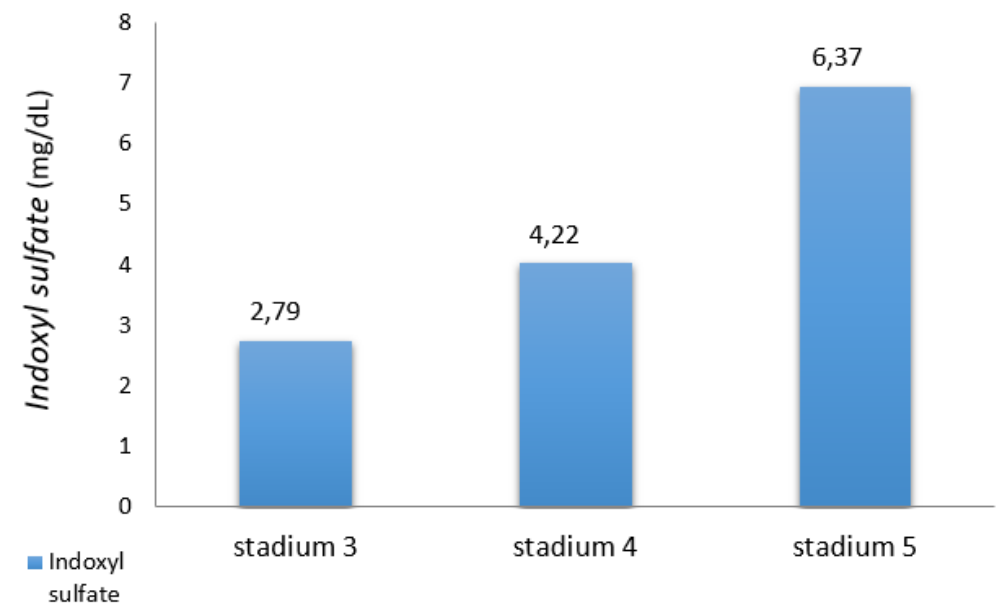

Fig. 1. Graphic of the mean level of indoxyl sulfate distribution based on the stage of CKD

From this study, the mean level of TAT complex was $12,61 \pm 2,49 \mathrm{ng} / \mathrm{mL}$. Based on the Kolmogorov-Smirnov test, this result was normally distributed ( $p>0.05)$.

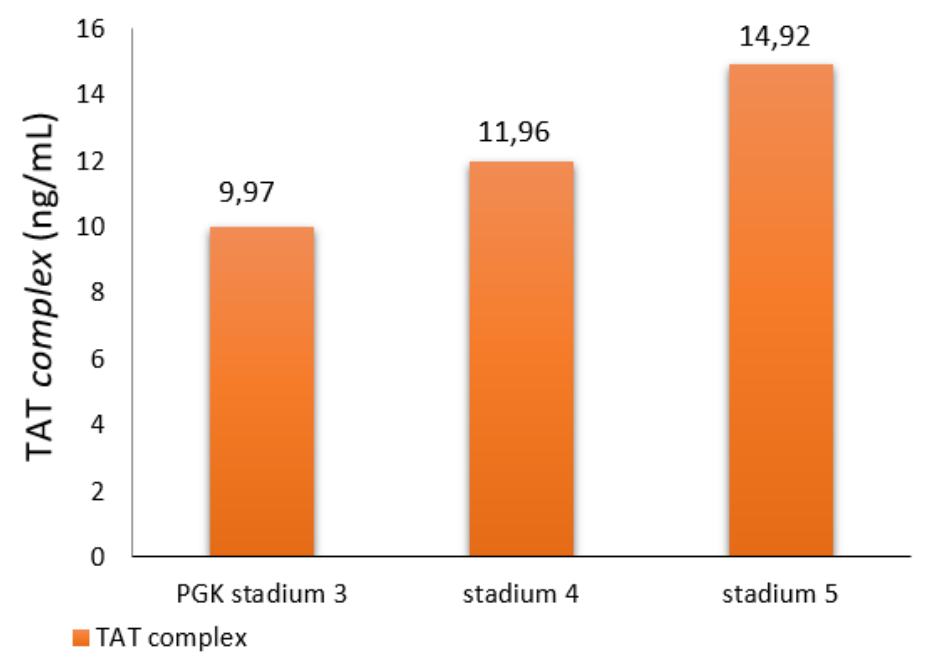

Fig. 2. Graphic of distribution of TAT complex mean level based on stage of CKD

This level was higher than control $(0.5-10 \mathrm{ng} / \mathrm{mL})$, and if tested with one sample t-test, there was significant difference $(\mathrm{p}<0.05)$. 


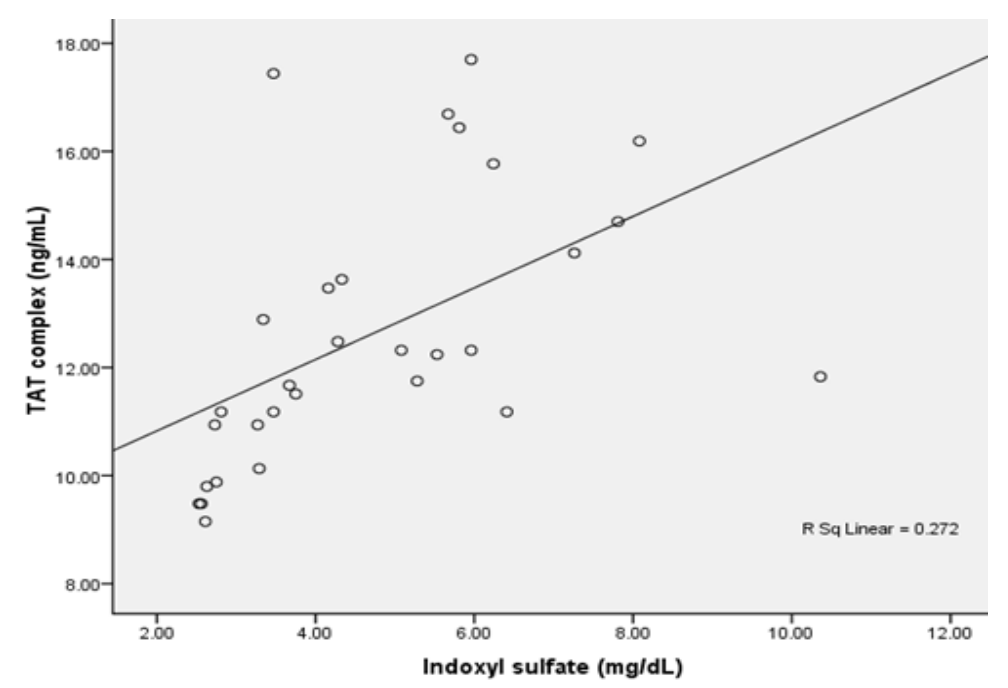

Fig. 3. Correlation between Indoxyl Sulfate with TAT complex in a patient with CKD

Based on the figure above, there was a positive correlation between the increase of TAT complex and indoxyl sulfate. The correlation was significant $(\mathrm{p}<0.05)$ with moderate gradation $(\mathrm{r}=0.522)$ by using the Pearson test.

\section{Discussion}

From 30 patients who met inclusion criteria, 13 persons (43.33\%) was male, and 17 persons (56.67\%) was female, with the most age was 51-60 years old (53.33\%), while the mean age was 50.5 years old.

Sagripanti et al. [12] reported the patient with CKD where 19 persons were male, and 10 persons were female with the mean age 54 \pm 11 years old. Meanwhile, Adams MJ et al. [25] reported the patient with CKD were 20 persons (54.05\%) were male, and 17 persons (45.94\%) were female with the mean age was $60 \pm 12$ years.

From National Health Interview Survey United States (2014) data, it reported that male patient and the female patient has an almost the same portion with the most age was 45-64 years old[13]. From several studies above, it showed that there is no significant difference in gender between male and female, while the most age is above 45 years old. It is almost the same with the prevalence of CKD in the world that increased $7.2 \%$ at population above 30 years old and estimated to increase along with the increase of age [14].

Hypertension is the main cause of CKD in this study (56.67\%), followed by gout nephropathy (20\%), chronic pyelonephritis (13.33\%), and obstructive nephropathy (10\%). Indonesian Kidney Registration Data (2014) also recorded the main etiology of CKD is hypertension kidney disease (37\%), followed by diabetic nephropathy (27\%), chronic glomerulonephritis (10\%), obstructive nephropathy (7\%), and gout nephropathy (1\%)[15]. Islam NS et al. [16] reported that the increase of CKD prevalence is associated with the increase of hypertension and diabetic incidences. 
Classification of CKD stages in this study was determined by GFR estimation with CKDEpi formula. We identified stage $3(26.67 \%)$, stage $4(33.33 \%)$, and stage $5(40 \%)$. This result is not too different with the study of Lin CJ et al. [17] that identified stage $3(23.32 \%)$, stage 4 (20.4\%), and stage $5(21.4 \%)$.

Indoxyl sulfate is one of the uremic toxins produced from tryptophan metabolism in food. Tryptophan is metabolized to indol by intestinal bacteria and converted to indoxyl sulfate after absorption and then excreted by renal. In a patient with CKD, the toxins will be accumulated in circulation because of the decrease of renal excretion function[17].

The normal level of indoxyl sulfate is not established till now. Data about the normal level of indoxyl sulfate in Indonesia is not available so that this study will not only measure the level of indoxyl sulfate in CKD patient but also in the healthy subject. The examination of indoxyl sulfate used HPLC technic. The normal level of indoxyl sulfate in this study was 2.53-10.36 $\mathrm{mg} / \mathrm{dL}$ with the mean level 4,70 $\pm 1,96 \mathrm{mg} / \mathrm{dL}$. This value is a little bit different from the study from Lin CJ et al. [27] in Taiwan; 2,1 $\pm 0,2 \mathrm{mg} / \mathrm{dL}$. Meanwhile, the data from European Uremic Toxin Work (2012) recorded the mean level of indoxyl sulfate in the uremic patient was 2,31 $\pm 1,30 \mathrm{mg} / \mathrm{dL}[18]$.

The mean level of indoxyl sulfate from CKD patient in this study was significantly higher than the normal subject $(1,86 \pm 0,30 \mathrm{mg} / \mathrm{dL})$. The mean level of indoxyl sulfate in a normal subject is almost the same as the study of Wu IW et al. [19] with the same examination technic $(1,24 \pm 0,17 \mathrm{mg} / \mathrm{dL})$.

The difference of indoxyl sulfate means level from several studies might be caused by the difference of sample number, staging of CKD and etiology of CKD that is investigated. CKD and its comorbidity will increase the accumulation and synthesis of indoxyl sulfate. Age, diet, oxidative stress, stage, and therapy could influence the population of intestinal microflora that also has a role in synthesis and accumulation of indoxyl sulfate[20].

The other factor that influences the level of indoxyl sulfate is a genetic factor. Viaene et al. [21] reported that genetic or hereditary factor played a role in indoxyl sulfate metabolism. This result was supported by the study of Benson et al. [22], he identified that intestinal microflora composition could affect the host genetic factor.

Based on the stage of CKD, level of indoxyl sulfate tends to increase along with the increase of CKD staging. The mean level of indoxyl sulfate in this study; stage $3(2.79 \mathrm{mg} / \mathrm{dL})$, stage 4 $(4.22 \mathrm{mg} / \mathrm{dL})$, and stage $5(6.37 \mathrm{mg} / \mathrm{dL})$. Lin CJ et al[17] reported the mean level of indoxyl sulfate in stage $3(0,32 \pm 0,03 \mathrm{mg} / \mathrm{dL})$, stage $4(0,54 \pm 0,36 \mathrm{mg} / \mathrm{dL})$, and stage $5(1,99 \pm 1,05$ $\mathrm{mg} / \mathrm{dL}$ ).

Barreto et al [63] also identified the median level of indoxyl sulfate in CKD; stage 2 and 3; $0.16(0.09-0.22) \mathrm{mg} / \mathrm{dL}$ and stage 4 and $5 ; 0.44(0.35-0.68) \mathrm{mg} / \mathrm{dL}$. Yoshikawa et al[24] identified the median level of indoxyl sulfate; stage 3 and $4 ; 1.0 \mathrm{mg} / \mathrm{dL}$ and $2.4 \mathrm{mg} / \mathrm{dL}$, and 20.7 $\mathrm{mg} / \mathrm{dL}$ in stage 5 .

In this study, we also identified the mean level of TAT complex in CKD patient $12,6 \pm 2,49$ $\mathrm{ng} / \mathrm{mL}$, it was higher than normal level $0,5-10 \mathrm{ng} / \mathrm{mL}$. The mean level of TAT complex in this study was $5,56 \pm 1,03 \mathrm{ng} / \mathrm{mL}$.

Study of Sagripanti et al[12] has the same exclution criteria with this study, it reported significant increase of TAT complex mean level $3,68 \pm 1,2 \mathrm{ng} / \mathrm{mL}$ ( $\mathrm{p}<0.001)$ compared to control $2,12 \pm 0,8 \mathrm{ng} / \mathrm{mL}$. Mean level of TAT complex from non-haemodialytic patient $2,94 \pm 0,58 \mathrm{ng} / \mathrm{mL}$ and haemodialytics patient $4,36 \pm 1,36 \mathrm{ng} / \mathrm{mL}$.

Nelson et al[24] reported mean level of TAT complex in CKD patient $36,2 \pm 6,73 \mathrm{ng} / \mathrm{mL}$ compared to control $2,4 \pm 0,08 \mathrm{ng} / \mathrm{mL}$. The increase of TAT complex means level is 15.08 times fold compared to control. This increase is much higher than mean level of coagulation activity 
F1+2 (3.79 times fold). Meanwhile, the study of Adams et al. [25] reported the mean level of TAT complex $3.2 \mathrm{ng} / \mathrm{mL}$ not significant compared to control.

The difference of TAT complex means level might be caused by the difference of sample number, etiology of CKD that is investigated, and age. The etiology of CKD such as hypertension, infection, inflammation, and age could induce hypercoagulable condition and accelerate the prothrombic process. This condition is related to endothelial dysfunction in CKD patient. Endothelial played a role in activating and detaining coagulation and fibrinolytic so that endothelial dysfunction could affect coagulation[26].

The other factor affecting coagulation activity in this study was obesity, hypercholesterolemia, and smoking. Obesity and hypercholesterolemia are associated with lipoprotein ability to activate thrombocyte and the coagulation cascade. Activated thrombocyte surface will enhance thrombin forming. Smoking might cause endothelial damage, thrombocyte adhesion increase, tPA reduction, and TFPI. All these factors could induce prothrombotic[27].

Besides that, genetic factor played a role in the tendency of hypercoagulation. Patients with congenital deficiency such as antithrombin deficiency, protein $\mathrm{C}$ deficiency, and protein $\mathrm{S}$ deficiency can reduce the ability to regulate thrombin forming that will be a predisposition of DVT and pulmonary embolism. Mutation of factor V Leiden will lead to regulation dysfunction of thrombin. On the other hand, prothrombin polymorphic disorder G20210A is related to prothrombin increase and risk of DVT and pulmonary embolism[28].

Not like the previous study, this study reported the mean level of TAT complex in each stage of CKD; stage $3(9.97 \mathrm{ng} / \mathrm{mL})$, stage $4(11.96 \mathrm{ng} / \mathrm{mL})$, and stage $5(14.92 \mathrm{ng} / \mathrm{mL})$. This data describe that mean level of TAT complex increased along with the increase of CKD stages.

The increase of TAT complex shows the increase of thrombin coagulation activity. The result of this study matched other several studies that show the increase of thrombosis risk in CKD patient already started since the early stage [3][29][30][31].

This study showed the increase of coagulation activity represented by TAT complex and level of indoxyl sulfate in the patient with CKD compared to normal subjects. These results are analyzed with the Pearson correlation test. It shows a significant positive correlation and moderate gradation $(\mathrm{r}=0.522)(\mathrm{p}<0.05)$. This indicates that the more increase of the level of Indoxyl sulfate, the more coagulation activity in CKD.

The association between the level of TAT complex and indoxyl sulfate indicates that uremic toxin might play a role in thrombosis occurrence of CKD. This study shows the importance to measure TAT complex and indoxyl sulfate in a patient with CKD.

This study also supported the development of proactive therapy for CKD patient such as oral adsorbent named AST-120. AST-120 act to absorb indol product in the intestine and excrete it via defecation so that the accumulation of uremic toxin will decrease[32]. We can also consider the use of indoxyl sulfate binder in order to reduce the production of indoxyl sulfate, in the end, it will reduce the risk of thrombosis occurrence in the patient with CKD.

\section{Conclusion}

There was a significant increase in thrombin coagulation activity in CKD, marked with the increase of TAT complex level. On the other hand, there is a significant increase of uremic toxin indoxyl sulfate in CKD. This study reported a significant positive correlation with moderate degree of correlation between the level of TAT complex and the level of indoxyl sulfate in patients with CKD. 


\section{References}

[1] Jalal DI, Chonchol M, Targher G. Disorders of hemostasis associated with chronic kidney disease. Semin Thromb Hemost; 36: 34-40 (2010)

[2] Pavord S, Myers B. Bleeding and thrombotic complications of kidney disease. Blood Rev; 25:271-78 (2011)

[3] Wattanakit K, Cushman M, Stehmann-Breen. Chronic kidney disease increases risk for venous thromboembolism. J Am Soc Nephrol;19: 135-40 (2008)

[4] Lutz J, Menke J, Sollinger D, Schinzel, Thürmel K. Haemostasis in chronic kidney disease. Nephrol Dial Transplant; 00: 1-12 (2013)

[5] Moshe S, Francis J, Chitalia V. Thrombosis in the uremic millieu-emerging role of thrombolome. Semin Dial; 28(2):198-205 (2015)

[6] Niwa T. Uremic toxicity of indoxyl sulfate. Nagoya J Med Sci; 72: 1-11 (2010)

[7] Wu IW, Hsu KH, Lee CC, Sun CY, Hsu HJ, Tsai CJ, et al. p-Cresyl sulfate and indoxyl sulfate predict progression of chronic kidney disease. Nephro Dial Transplant: 1-9 (2010)

[8] Kikuchi K, Itoh Y, Tateoka R. Metabolomic analysis of uremic toxins by liquid chromatography/ electrospray ionization-tandem mass spectrometry. J Chromatogr B; 878: 1662-8 (2010)

[9] Gondouin B, Cerini C, Dou L, Sallée M, Duval-Sabatier A, UGent AP,et al. Indolic uremic solutes increase tissue factor production in endothelial cells by the aryl hydrocarbon receptor pathway. Kidney Int; 84: 733-744 (2013)

[10] Chitalia CV, Shivanna S, Martorell J, Malcells M, Bosch I, Kolandaivelu K et al. Uremic serum and solutes increase post-vascular interventional thrombotic risk through altered stability of smooth muscle cel tissue factor. Circulation; 217: 363-76 (2013)

[11] Gao C, Xie R, Yu C, Ma R, Dong W, Meng H et al. Thrombotic role of blood and endothelial cells in uremia through phosphatydilserine exposure and microparticle release. Plos One; 10(11): 1-16 (2015)

[12] Sagripanti A, Cupisti A, Baicchi U, Ferdeghini M, Morelli E, Barsotti G. Plasma parameters of the prothrombotic state in chronic uremia. Nephron; 63(3): 273-8 (1993)

[13] Summary Health Statistics: National Health Interview Survey, Diakses dari http://www.cdc.gov/nchs/fastats/kidney-disease.htm(2014)

[14]Zhang QL, Rothenbacher D. Prevalence of chronic kidney disease in population based studies: systematic review. BMC Public Health; 8: 117 (2008)

[15]7 th Report Of Indonesian Renal Registry. Diakses dari: www.indonesianrenalregistry.org/data/indonesian\%20renal\%20registry\%202014.pdf( 2014)

[16] Islam TM, Fox CS, Mann D, Muntner P. Age related associations of hypertension and diabetes mellitus with chronic kidney disease. BMC Nephrol; 10: 17-20 (2009)

[17] Lin CJ, Chen HH, Pan CF, Chuang CK, Wang TJ, Sun FJ et al. p-Cresyl sulfate and indoxyl sulfate level at different stages of chronic kidney disease. J Clin Lab Anal; 25: 191-7 (2011)

[18] Duranton F, Cohen G, Smet RD, Rodriguez M, Jankowski J, Vanholder R, et al. Normal and pathologic concentrations of uremic toxins. J Am Soc Nephrol; 23: 1258 70 (2012)

[19] Wu IW, Hsu KH, Sun CY, Tsai CJ, Wu MS, Lee CC. Oral adsorbent AST-120 potentiates the effects of erythropoietin stimulating agents on stage 5 chronic kidney 
disease patients: a randomized crossover study. Nephrol Dial Transplant ,29; 1719-27 (2014)

[20] Ellis RJ, Small DA, Johnson DW, Francis R, Vietta L, Gobe GC, et al. Indoxyl sulphate and kidney disease: causes, consequences and interventions. Centre for kidney disease research. (2014)

[21] Viaene L, Thijs L, Jin Y, Liu Y, Gu Y, Meijers B, et al. Heritability and clinical determinants of serum indoxyl sulfate and p-cresyl sulfate, candidate biomarkers of the human microbiome enterotype. Plos One; 9(5): 1-7 (2014)

[22] Benson AK, Kelly SA, Legge R, Ma F, Low SJ. Individuality in gut microbiota composition is a complex polygenic trait shaped by multiple environmental and host genetic factors. Proc Natl Acad Sci USA; 107: 18933-18938 (2010)

[23] Barreto Fc, Barreto DV, Canziani ME, Tomiyama C, Higa A, Mozar A, et al. Association between indoxyl sulfate and bone histomorphometry in pre-dialysis chronic kidney disease patients. J Bras Nefrol;36(3):289-296 (2014)

[24] Yoshikawa D, Ishii H, Suzuki S, Takhesita K, Kumagai S, Hayashi M, et al. Plasma indoxyl sulfate and estimated glomerular filtration rate association with long term clinical outcome in patients with coronary artery disease. Circ J; 78: 2477-82 (2014)

[25] Adams MJ, Irish AB, Watts GF, Oostryk R, Dogra GK. Hypercoagulability in chronic kidney disease is associated with coagulation activation but not endothelial dysfunction. Thrombosis Research; 123: 374-80 (2008)

[26] Alfirevic Z, Alfirevic I. Hypercoagulable state, pathophysiology, classification and epidemiology. Clin Chem Lab Med; 48(1): s15-s26 (2010)

[27] Plat A. Can you recognize a patient at risk for a hypercoagulable state? JAAPA; 21(12): 20-26 (2008)

[28] Rosendaal FR, Reitsma PH. Genetics of venous thrombosis. J of Thrombosis and Haemostasis; 7(1): 301-04 (2009)

[29] Wright RS, Reeder GS, Herzog CA. Acute myocardial infarction and renal dysfunction: a high-risk combination. Ann Intern Med; 137: 563-70 (2002)

[30] Yahalom G, Kivity S, Segev S, Sidi Y, Kurnik D. Estimated glomerular filtration rate in a population with normal to mildly reduced renal function as predictor of cardiovascular disease. Eur J Prev Cardiol;21(8):941-80 (2014)

[31] Ocak G, Lijfering WM, Verduijn M, Dekker FW, Rosendaal FR, Cannegieter SC, et al. Risk of venous thrombosis in patients with chronic kidney disease: identification of high-risk groups. J Thromb Haemost; 11: 627-33 (2013)

[32] Niwa T. Role of indoxyl sulfate in the progression of chronic kidney disease and cardiovascular disease: experimental and clinical effects of oral sorbent AST-120. Ther Apher Dial; 15(2): 120-4 (2011) 